\title{
The Effect of Users' Motivations and Interactivity on Online Word of Mouth*
}

\author{
Seolwoo PARK ${ }^{1}$
}

Received: August 01, 2020 Revised: September 06, 2020 Accepted: September 10, 2020

\begin{abstract}
The purpose of this study is to investigate the impacts of two different kinds of interactivity, such as user-to-user and user-to-media interaction, on the relationship between SNS motivation and online word of mouth (WOM). An online survey was conducted with SNS users in Korea. Using the convenience-sampling method, 300 surveys were collected and 295 were used in the actual analysis after excluding data with careless responses or missing values. Hypotheses were tested using Structure Equation Model (SEM) and path analysis by using AMOS22. The results indicate that four different SNS motivations (self-expression, relational, fun, and browsing motivation) have a partially significant positive effect on perceived user-to-user and user-to-media interaction in SNS. Although both user-to-user interactivity and user-to-media interactivity were found to have a significant effect on online word of mouth, by comparing the standardized regression coefficients in these relationships, it was found that user-to-user interactivity has a greater effect on online WOM than user-tomedia interactivity. These results show that the motivated SNS users want to express their desire to communicate with other users in contrast than their desire to learn media functions when motivated SNS users reveal their personalities, knowledge, and abilities. Theoretical and managerial implications are discussed.
\end{abstract}

Keywords: SNS Motivation, User Interactivity, Media Interactivity, Online Word of Mouth

JEL Classification Code: M16, M30, M31

\section{Introduction}

The Social Network Services (SNSs) are considered as an ideal tool for "electronic word of mouth" (also known as eWOM) as users can engage in various relationships through participation, and consumers can voluntarily generate and disseminate information about products they have used or services they have experienced among those with whom they have relationships. Online word of mouth spreads quickly and easily over the Internet and has a significant ripple effect,

*Acknowledgements:

This work was supported by the research grant of Jeju National University in 2020.

${ }^{1}$ First Author and Corresponding Author. Assistant Professor, Department of Business Administration, College of Economics \& Commerce, Jeju National University, Korea [Postal Address: 102 Jejudaehak-Ro, Jeju-Si, Jeju, 63243, Korea]

Email: swpark@jejunu.ac.kr

() Copyright: The Author(s)

This is an Open Access article distributed under the terms of the Creative Commons Attribution Non-Commercial License (https://creativecommons.org/licenses/by-nc/4.0/) which permits unrestricted non-commercial use, distribution, and reproduction in any medium, provided the original work is properly cited. making it a popular communication channel for marketers to consider using. This effect is further promoted by new media and mobile environments, such as SNSs, which have very strong user control and a highly interactive nature.

In previous research related to new media, studies that focus on users' motivations for use, media acceptance, usage intention, attitude, and satisfaction have been relatively numerous. Furthermore, the most important influencing factors in the use of various types of new media such as social media, online communities, and Internet shopping malls are motivations for use. It is the core of a company's SNS marketing to create an environment as a communication space that can promote two-way communication between users and companies or other users, rather than unilateral message acceptance by companies by inducing the continuous participation of consumers. Therefore, the ability to grasp the needs of consumers and supply the products and services they need and want through such participation will serve as an important factor for increasing a company's competitiveness. SNSs represent an immense number of users worldwide, giving companies the opportunity to reach out to consumers and promote their products and brands without geographic 
or time restrictions. Despite the high number of expected effects, research on the influence of SNSs' driving force on the use of real users has not been conducted.

This study aims to explore the need for research with regard to SNS marketing that focuses on the new media environment and to examine the effect of motivation for using SNSs for online word-of-mouth activities according to the interaction within SNSs from an integrated perspective. This study's primary aim is to enable consumers to create and share information on SNSs and to build long-term relationships through active communication between businesses and consumers by providing guidelines useful for establishing appropriate promotional strategies for each target group by identifying users' motivations for using SNSs (Facebook, Twitter, Instagram, etc.) that have been actively used recently. In addition, a second purpose of the study is to provide basic data to derive specific strategic implications for SNS marketing by dividing the types of SNSs' interactivity into two types based on their theoretical background and examining the impact of each type of interactivity on online word of mouth for products and services.

\section{Literature Review}

With the explosive increase in the number of SNS users, consumers who were previously considered to just recipients of information, have played a role as producers and intermediaries of information as a node on the network. Therefore, some researchers have attempted to learn more about people's motives for using SNSs in order to understand "why they use SNSs" (Cho, 2018; Salehan, Kim, \& Kim, 2017; Wang, Jackson, Wang, \& Gaskin, 2015).

According to Katz, a researcher who established the adoption model of new media based on the use and gratification theory (UGT), a motive is defined as a "psychological mechanism that enables individuals to activate and maintain certain actions" as a stage in which they prepare for the pursuit of certain actions or goals. Considering a motive for using new media, including SNSs, based on Katz's UGT, it has been confirmed that it is a theory that motives which leads to use of media by individuals is primarily to meet their psychological needs, and that they use media on the premise that they are active and goal-oriented (Katz, Gurevitch, \& Hass, 1973). In order to attract SNS users' voluntary and positive participation, there has been a need for motives that can lead them to attract and maintain the behavior, and many studies have attempted to understand motives for using SNSs thus far. Representative motives for using new media are known to be a cognitive motive for seeking information, a recreational motive for a change in atmosphere, and a motive for identity that induces reinforcing effects among others (Kim, Ko, \& Kim, 2015; Lee, Kang, \& Ahn, 2017; $\mathrm{Xu}$, Ryan, Prybutok, \& Wen, 2012), which are based on the
UGT, meaning that individuals choose media for themselves through their motives, unlike the characteristics of existing users who simply accept messages from various media.

Looking at previous studies conducted on motives for using SNSs, Wang \& Fesenmaier (2004) categorized four motives for engaging in online communities: a functional one for the purpose of obtaining information; a social one for building relationships with others; a playful motive for acquiring entertainment and enjoyment; and lastly, a psychological motive that enables self-expression. By contrast, Hennig-Thurau, Gwinner, Walsh, \& Gremler (2004) and Brandtzæg \& Heim (2009) classified these motives as altruistic, self-expressive, relational, and economic, as well as a motive for problem-solving, and informational, recreational, and social motives and a motive for personal identity, respectively. Based on UGT, this study has classified the motives for using SNSs into self-expressive, relational, and recreational motives, in addition to a motive for information-seeking in order to examine each one.

\subsection{SNS Motivation}

In general, people have a variety of needs, and this is a leading factor in various decision making or behavior (Venkatesh \& Sharma, 2015; Won \& Kim, 2020). In regard to communication, it has been shown that people who are proficient in self-expression enhance their value by expressing themselves while promoting the development of mutual relationships by allowing others to express themselves well (Alberti \& Emmons, 1978; Choi, Wang, \& Chen, 2019). Tajfel and Turner (2001) said that self-expression can be viewed as an effort to inform other users of their presence as an intrinsic motive for using SNSs, which can be explained through the theory of social identity based on self-concept. In regard to the desire to express their identity, information-sharing takes place immediately, and it has recently come to the fore as an important factor as the number of users who want to share their daily lives increases, in addition to the constant use of SNSs. Users who use SNSs to express themselves tend to expose themselves openly online. Existing studies on self-exposure have found that self-exposure is preceded by the desire for an affinity to create and maintain relationships with others, and the more they are exposed online, the more intimate and trustworthy the relationship becomes by delivering empathetic feelings to them, so it is confirmed that it plays an essential role in developing a mutual relationship with them (Shapiro \& Swensen, 1977).

A relational motive involves the reasons that users want to form and maintain social networks through communication with other users (Hennig-Thurau et al., 2004). Therefore, users who use SNSs have an interpersonal purpose to establish relationships with acquaintances or friends according to a relational motive. Also, for users with such tendencies, it is considered that the propensities of users will 
take a communicational attitude that expresses their friendly expression to the other side. In addition, looking at the findings of Brooks (1957) that personal connection as a motive for social relations is most effective in bringing about changes in people's opinions and behaviors, it can be confirmed that people with strong relational motives are strongly influenced by those with whom they have a personal and deep affinity. These previous studies have shown that the interest of users who use SNSs with a relational motive is to maintain acquaintances with and share fellowship with others.

The motivation to have fun is also called a pleasure or recreational motivation and has already been identified as a motive for many behavioral variables (Park, 2018). Users of certain media, such as the Internet or SNSs, regard the use of media as a form of play and use it for relaxation, entertainment, and leisure. Accordingly, it can be inferred that people will upload useful content to SNS for their enjoyment and share it with other users.

Browsing motivation is the main motive for using media such as the Internet as well as SNSs, and its aim is to obtain useful information from other users (Wang \& Fesenmaier, 2004). Having the motivation to search for information is connected with acquiring the information that one wants or needs, but it may be assumed that the act of searching for information itself is the motivation. When the act of searching for information itself serves to motivate users, there may be cases where the information users have is limited, and there are also cases where people do not know what information they want.

\subsection{Interactivity}

The rising trend of Internet use, a tool of communication, has led researchers to conduct numerous studies to identify those factors that make this tool stand out among other popular media, and among them, a factor receiving the most attention is interactivity (Tobing, Suroso, Halim, \& Alif, 2020). Interactivity, the most remarkable characteristic that distinguishes this new medium from existing media, is the most important word in new media technology (Usher, 2016) and is used as an important concept to measure the effectiveness of computer-mediated communication (Lew, Walther, Pang, \& Shin, 2018; McMillian \& Hwang, 2002).

The concept of interactivity can be described in various ways. Johnson, Bruner II, \& Kumar (2006) suggested three types of interactivity approaches: an interpersonal perspective, a mechanical perspective, and an integrated perspective that combines the first two according to the situation (Liu \& Shrum, 2002). Jensen (1998) divided the mechanical message into two dimensions: interaction between media and between people, considering it as a concept of media, and Hoffman \& Novak (1996) noted a need to study it by dividing it into human computer interaction and interactions between users.
Regarding the concept of interpersonal interactivity and its component factors, Newhagen, Cordes, \& Levy (1995) stated that it is the perception of the interaction between the individual and others. Downes \& McMillan (2000) related it to the perception of time and place; Schumann, Artis, \& Rivera (2001) identified the choice of consumers for interactions, in terms of communication, considered the concept of interpersonal interactivity as how closely messages are connected, and used feedback and responsiveness to messages as component factors (Burgoon, Bonito, Bengtsson, Ramirez Jr, Dunbar, \& Miczo, 1999).

When it comes to interactivity from a mechanical point of view, the degree of interactivity depends on the technology level of media, and the interaction is measured based on the structural elements of the media. The types of interactivity from the mechanical perspective include interactivity with media and with information, and the conceptual boundary between the two is unclear because there are also researchers who argue that the "media is the message" (McLuhan \& McLuhan, 1994).

Based on the previous studies on interactivity, this study aimed to focus on the interactivity in the mechanical and interpersonal aspects of the media on the cognitive perspective being recognized through the direct experiences of users. In the case of interactivity between users, it can explain the degree to people feel that they are forming an emotional relationship with each other through an emotional bond (Burgoon et al., 1999). User-media interactivity explains whether to provide personalized content that meets the needs of users not from an emotional bond but from a personal point of view (Dholakia, Zhao, Dholakia, \& Fortin, 2000). Interactive communication is defined not only as mutual discourse (Burgoon et al., 1999) but also as the ability to provide feedback, and this study has attempted to measure interactivity from an interpersonal perspective according to the former concept.

\subsection{Online Word of Mouth}

The advent of the Internet has also revolutionized the word of mouth. According to Katz \& Lazarsfeld (1966), word of mouth among consumers were initially defined as the act of exchanging marketing information that played an essential role in transforming consumer attitudes and behaviors toward products and services. Online word of mouth was defined as being available to a large number of people and organizations on the Internet and as a positive or negative opinion about products and services produced by potential, realistic, and official consumers (HennigThurau et al., 2004). For online word of mouth from various channels such as blogs, emails, virtual communities, SNSs, etc., as mentioned above, SNSs are considered an ideal tool.

Previous studies conducted on online word of mouth revealed that the spreading power of word of mouth is 
an important factor directly affecting the sales growth of companies (Eisingerich, Auh, \& Merlo, 2014). Moreover, it is well known that it has an indirect effect on increasing consumers' favorability and credibility toward brands and products. It was also found that SNSs have a greater influence on consumers' decision-making about purchasing products than other media because recommendations from acquaintances or users on SNSs have higher reliability. It has been shown that the amount of word of mouth information on SNSs is much higher than that of offline word of mouth (Brown, Broderick, \& Lee, 2007).

According to Chu \& Kim (2011), SNSs have the potential to promote and create online word of mouth in the marketplace, but studies on why and how this occurs in the online social media context remains insufficient. Online word of mouth on SNSs can be considered through three aspects: seeking, providing, and delivering opinions. The method of sharing information is generally divided into an opinion leader and an opinion reader, and the interactive characteristic of SNSs makes it possible to engage in active and interactive online word-of-mouth in which a person can perform various roles.

This study attempts to define word-of-mouth activities as information about products or service users' experiences produced and shared on SNSs or as the process of searching for information produced by other users.

\subsection{Hypotheses}

In order to conduct a study on perceived user-to-user and user-to-media interactivity and online word of mouth activity according to motivation for using SNS, Burgoon et al. (2002), Mason (1994), Newhagen et al. (1995) referenced the relationship between SNS motivation and user-touser interactivity, and Dholakia et al. (2000), McMillan (2002), and Straubhaar and LaRose (1998) referenced the relationship between SNS motivation and user-to-media interactivity. Regarding the perceived interactivity and word-of-mouth intention, the following hypotheses were developed by referring to the studies of Chu and Kim (2011) to align with this study:

H1: SNS users' self-expressive motivation has a positive effect on user-to-user interactivity.

H2: SNS users' self-expressive motivation has a positive effect on user-to-media interactivity.

H3: SNS user's relational motivation has a positive effect on user-to-user interactivity.

H4: SNS user's relational motivation has a positive effect on user-to-media interactivity.

H5: SNS user's fun motivation has a positive effect on user-to-user interactivity.

H6: SNS user's fun motivation has a positive effect on user-to-media interactivity.
H7: SNS user's browsing motivation has a positive effect on user-to-user interactivity.

H8: SNS user's browsing motivation has a positive effect on user-to-media interactivity.

H9: User-to-user interactivity has a positive effect on online word of mouth.

H10: User-to-media interactivity has a positive effect on online word of mouth.

\section{Research Methods}

\subsection{Research Model}

Based on the review above, the research model is depicted in Figure 1. The model shows that four different SNS motivations are likely to influence eWOM via two different interactivities (see Figure 1).

In this study, SNS motivations were measured by four dimensions (self-expression, relationship, fun, and browsing. Interactivities are divided by user-user and user-media, and eWOM is used as the most important dependent variable.

\subsection{Sampling and Data Collection}

To conduct this research, an online survey was conducted with SNS users in Korea. Using the convenience sampling method, 300 surveys were collected. By excluding data with careless responses or missing values, 295 surveys were used in the actual analysis.

Based on a demographic analysis of the participants, $49.2 \%$ were male and $50.8 \%$ were female, and their age distribution was as follows: $10.1 \%$ were younger than 20 years; $40.3 \%$ were in their $20 \mathrm{~s} ; 35.3 \%$ were in their $30 \mathrm{~s}$, and $14.3 \%$ were over 40 years of age. The average SNS usage time per week for SNS users was distributed as $11.4 \%, 21.2 \%$, $19.7 \%, 16.1 \%, 15.2 \%$, and $16.4 \%$ for less than 1 hour, 1 hour to less than 3 hours, 3 hours to less than 5 hours, 5 hours to less than 7 hours, 7 hours to less than 9 hours, and more than 9 hours, respectively.

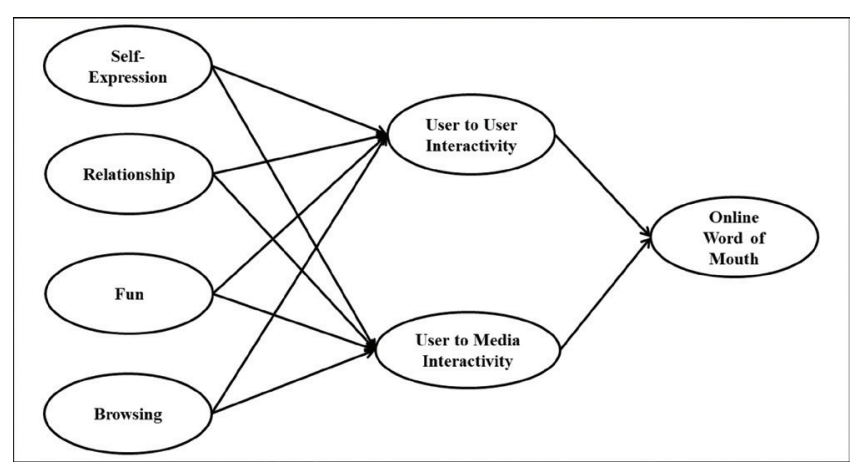

Figure 1: Research model 


\subsection{Measurement}

In order to measure the constructs in the suggested model, validated measurement items were adapted from literature reviews. From the basic data of the study, demographic variables were measured by nominal measures. In addition, the derived items were measured on a 7-point Likert-type scale, anchored from strongly disagree (1) to strongly agree (7). To measure the concepts of SNS user's motivations such as self-expression, relation, fun, and browsing, 12 items were compiled based on the previous literature (Henning et al., 2004; Kim \& Jang, 2019; Papacharissi \& Rubin, 2000; Wang $\&$ Fesenmaier, 2004). To measure interactivities between user and user and user and media as defined by Burgoon et al. (2002), Dholakia et al. (2000), and Vendemia (2017), three items were used for each. Finally, five items were used to measure eWOM derived from Mishra et al. (2018) and Venkatesh et al. (2003).

\section{Results}

\subsection{Assessment of reliability and validity measurement scales}

To examine the measurement properties of the measures used in this study, a confirmatory factor analysis was conducted. Reliability and validity of measurement scales developed for each stage were run through SPSS 22.0 and AMOS 22.0. As shown in Table 1, Cronbach's alphas for all factors were as found to be larger than 0.7 (ranging from 0.787 to 0.940 ), and all constructs were deemed reliable. To verify convergent validity, averaged variance extracted (AVE) and composite reliability (CR) were examined; AVE should be higher than 0.5 and CR should be higher than 0.6 (Fornell \& Larcker, 1981). All constructs have higher than $0.5 \mathrm{AVE}$ (ranging from 0.574 to 0.797 ) and $0.6 \mathrm{CR}$ (ranging from 0.615 to 0.879 ) (see Table 1).

Table 1: Construct reliability and validity

\begin{tabular}{|c|c|c|c|c|c|}
\hline Construct & Variables & Loading & $\begin{array}{c}\text { Cronbach's } \\
\text { alpha }\end{array}$ & AVE & CR \\
\hline \multirow{3}{*}{ Self-Expression } & SE1 & 0.713 & \multirow{3}{*}{0.831} & \multirow{3}{*}{0.641} & \multirow{3}{*}{0.675} \\
\hline & SE2 & 0.827 & & & \\
\hline & SE3 & 0.856 & & & \\
\hline \multirow{3}{*}{ Relation } & RE1 & 0.659 & \multirow{3}{*}{0.787} & \multirow{3}{*}{0.574} & \multirow{3}{*}{0.615} \\
\hline & RE3 & 0.750 & & & \\
\hline & RE4 & 0.852 & & & \\
\hline \multirow{3}{*}{ Fun } & FU1 & 0.835 & \multirow{3}{*}{0.911} & \multirow{3}{*}{0.776} & \multirow{3}{*}{0.844} \\
\hline & FU2 & 0.917 & & & \\
\hline & FU3 & 0.887 & & & \\
\hline \multirow{2}{*}{ Browsing } & BR1 & 0.942 & \multirow{2}{*}{0.885} & \multirow{2}{*}{0.797} & \multirow{2}{*}{0.703} \\
\hline & BR2 & 0.843 & & & \\
\hline \multirow{3}{*}{ User to User Interactivity } & UUI1 & 0.867 & \multirow{3}{*}{0.841} & \multirow{3}{*}{0.667} & \multirow{3}{*}{0.790} \\
\hline & UUI2 & 0.890 & & & \\
\hline & UUI3 & 0.675 & & & \\
\hline \multirow{3}{*}{ User to Media Interactivity } & UMI1 & 0.823 & \multirow{3}{*}{0.891} & \multirow{3}{*}{0.734} & \multirow{3}{*}{0.800} \\
\hline & UMI2 & 0.859 & & & \\
\hline & UMI3 & 0.887 & & & \\
\hline \multirow{5}{*}{ Online Word of Mouth } & WOM1 & 0.889 & \multirow{5}{*}{0.940} & \multirow{5}{*}{0.764} & \multirow{5}{*}{0.879} \\
\hline & WOM2 & 0.924 & & & \\
\hline & WOM3 & 0.918 & & & \\
\hline & WOM4 & 0.885 & & & \\
\hline & WOM5 & 0.739 & & & \\
\hline
\end{tabular}

$\chi 2(188)=337.723, p<0.001, G F I=0.905, C F I=0.967, N F I=0.928, R M S E A=0.052$ 
Discriminant validity was assessed by comparing squared correlations among the constructs against variances extracted by their respective factors (Hair, Black, Babin, \& Anderson, 2010). As shown in Table 2, all squared correlations were less than variances extracted. This result implies that the variances shared among variables (squared correlation coefficients) were less than the variances explained by each construct (variances extracted), thereby demonstrating that all indicators are better explained by their respective constructs than other constructs explaining indicators in different constructs. The test shows that all constructs adopted in the current study are different from one another and, thus, have discriminant validity (Koo \& Lee, 2011) (see Table 2).

\subsection{Testing of Hypotheses}

The structural model was tested as shown in Figure 1. These results demonstrate that the model at large reflects a good fit with the data as demonstrated by the goodness-of-fit statistics $(\chi 2(\mathrm{df}=199)=569.579, p<0.001, G F I=0.849$, $C F I=0.917, I F I=0.918, R M S E A=0.080)$ displayed in Table 3. All of the proposed hypotheses are accepted except $\mathrm{H} 2$ and 5 (see Table 3).

Table 2: Test of discriminant validity

\begin{tabular}{|c|c|c|c|c|c|c|c|}
\hline & SE & RE & FU & BR & UUI & UMI & wOM \\
\hline SE & 0.641 & & & & & & \\
\hline \multirow{2}{*}{ RE } & 0.629 & 577 & & & & & \\
\hline & $(0.396)$ & $0.5 / 4$ & & & & & \\
\hline \multirow{2}{*}{ FU } & 0.058 & 0.293 & & & & & \\
\hline & $(0.003)$ & $(0.086)$ & 0.776 & & & & \\
\hline \multirow{2}{*}{$\mathrm{BR}$} & 0.116 & 0.426 & 0.481 & 707 & & & \\
\hline & $(0.013)$ & $(0.181)$ & $(0.231)$ & 0.197 & & & \\
\hline \multirow{2}{*}{ UUI } & 0.116 & 0.352 & 0.463 & 0.558 & 0667 & & \\
\hline & $(0.013)$ & $(0.124)$ & $(0.214)$ & $(0.311)$ & $0.00 r$ & & \\
\hline \multirow{2}{*}{ UMI } & 0.459 & 0.590 & 0.224 & 0.328 & 0.397 & 0721 & \\
\hline & $(0.211)$ & $(0.348)$ & $(0.050)$ & $(0.108)$ & $(0.158)$ & 0.134 & \\
\hline \multirow{2}{*}{ WOM } & 0.387 & 0.446 & 0.274 & 0.324 & 0.324 & 0.503 & 0764 \\
\hline & $(0.150)$ & $(0.199)$ & $(0.075)$ & $(0.105)$ & $(0.105)$ & $(0.253)$ & 0.164 \\
\hline
\end{tabular}

Note. The figures in the sub-diagonal are correlation coefficients (squared correlations) and the bold figures in the diagonal represent variances extracted.

Table 3: Hypothesis Analysis

\begin{tabular}{|c|c|c|c|c|c|}
\hline \multicolumn{2}{|r|}{ Hypothesis } & Beta & Standard Error & t-value & Result \\
\hline $\mathrm{H} 1$ & Self-expression -> User to User Interactivity & 0.261 & 0.058 & $4.490 * * *$ & Accept \\
\hline$H 2$ & Self-expression -> User to Media Interactivity & -0.002 & 0.047 & -0.047 & Reject \\
\hline $\mathrm{H} 3$ & Relation -> User to User Interactivity & 0.460 & 0.077 & $5.993^{* * *}$ & Accept \\
\hline $\mathrm{H} 4$ & Relation -> User to Media Interactivity & 0.154 & 0.058 & $2.648^{* *}$ & Accept \\
\hline H5 & Fun -> User to User Interactivity & 0.060 & 0.056 & 1.071 & Reject \\
\hline $\mathrm{H} 6$ & Fun -> User to Media Interactivity & 0.228 & 0.050 & $4.591^{* * *}$ & Accept \\
\hline $\mathrm{H} 7$ & Browsing -> User to User Interactivity & 0.315 & 0.048 & $6.532^{* * *}$ & Accept \\
\hline H8 & Browsing -> User to Media Interactivity & 0.141 & 0.051 & $2.785^{* *}$ & Accept \\
\hline $\mathrm{H} 9$ & User to User Interactivity -> Online word of Mouth & 0.529 & 0.075 & $7.008^{* * *}$ & Accept \\
\hline $\mathrm{H} 10$ & User to Media Interactivity -> Online word of Mouth & 0.223 & 0.083 & $2.707^{* *}$ & Accept \\
\hline
\end{tabular}

Note: ${ }^{* * *}$ and ${ }^{* *}$ indicates significant at $1 \%$ and $5 \%$ level of significance based on t-statistics 
H1 and 2 posit the relationship between the self-expressive motivation and interactivities. The results indicate that selfexpressive motivation has a significant impact on user-touser interactivity ( $\mathrm{H} 1: \beta=0.261, \mathrm{p}<0.001)$. while there is no significant relationship between self-expressive motivation and user-to-media interactivity ( $\mathrm{H} 2: \beta=-0.002$, n.s.). In the relationship between relational motivation and interactivities, it was confirmed that relational motivation had a significant effect on both user-to-user interactivity (H3: $\beta=0.460, \mathrm{p}<$ $0.001)$ and user-to-media interactivity $(\mathrm{H} 4: \beta=0.154, \mathrm{p}<$ $0.01)$. In the relationship between motivation for enjoyment and interactivities, motivation for enjoyment had a significant effect on user-to-media interactivity (H6: $\beta=0.228, \mathrm{p}<$ 0.001 ) but did not have a significant effect on user-to-user interactivity (H5: $\beta=0.060$, n.s.). In the relationship between browsing motivation and interactivities, it was confirmed that browsing motivation had a significant effect on both user-touser interactivity $(\mathrm{H} 7: \beta=0.315, \mathrm{p}<0.001)$ and user-to-media interactivity $(H 8: \beta=0.141, p<0.01)$. Finally, in the relationship between interactivities and eWOM, it was confirmed that both two interactivities had a significant effect on online word of mouth (H9: $\beta=0.529, \mathrm{p}<0.001 ; \mathrm{H} 10: \beta=0.223, \mathrm{p}<0.01)$.

\section{Conclusions}

This study investigated the relationship between SNS users' motivation and online word of mouth via two different interactivities, user-to-user and user-to-media. First, hypotheses 1 to 8 that SNS usage motivation will have a positive effect on perceived interactivity in the SNS were partially accepted. Specifically, self-expression, relational, and browsing motivations were statistically supported as drivers for SNS use that positively influenced user-to-user interactivity. However, there is no significant relationship between enjoyable motivation and user-to-user relationship.

These results can be interpreted as more motivated SNS users are to reveal their personalities, knowledge, and abilities, the stronger their desire to communicate with other users will be in contrast than their desire to learn media functions. In addition, users with strong relational motivation aimed at forming and maintaining relationships with others and people with strong motivation to acquire more information can be interpreted in the same context. As a result of reflecting the social characteristics of SNS well, SNS contributes to the formation of social capital. Therefore, it can be seen that social network ties, bonds, and communities are very closely related to human network motivation.

By contrast, relational, enjoyable, and browsing motivations were found to be the driving factors that have a significant positive effect on user-to-media interactivity, and self-expressive motivation had no influence on user-tomedia interaction. These results can be interpreted by noting that as the motivation for SNS users to use entertaining and informational content increases, interactivity increases through a functional aspect under the user's control.

Next, both user-to-user and user-to-media interactivity were found to have a significant effect on online word of mouth. By comparing the standardized regression coefficients in this relationship, it was found that user-to-user interactivity has a greater effect on eWOM than user-to-media interactivity (BUS-US $=0.437$ vs. BUS-ME $=0.159$ ). This result can be interpreted by stating that the interaction between the individual's perception and the interactivity in terms of media characteristics differ because the interactivity experienced by the user can induce interactivity as a media characteristic and other users' reactions. In addition, it can be stated that simply acquiring skills and recognizing high interactivity does not act as a decisive influence variable on viral activities.

The findings of this paper are summarized as follows. First, it can be seen that the results of classifying the differences between each effect were derived based on the responses that users experienced and that the perceived effect of interactivity in an interpersonal and functional viewpoint was not clear. In addition, the results show that, in order to induce active information searching and sharing, it is absolutely necessary to enhance interactivity through increased communication between users and the formation of intimacy on SNSs. Second, self-expressive, relational, and browsing motives showed a significant influence on interpersonal (user-to-user) interaction in SNS, while the degree of functional (user-tomedia) interaction is relational, enjoyable, and browsing motivation that were identified as determinants. This is a result that reflects the social characteristics of SNS. As SNS contributes to the formation of social capital, it can be seen that the key components of social capital, such as bonding and solidarity, have a very close relationship with human network motives such as self-expression and relationship. Finally, both user-to-user interactivity and user-to-media interactivity in SNSs have a significant effect on online word-of-mouth activity, but the result is that user-to-user interaction is more influential. Through these results, the control that is allowed to users is strong, and whether or not to provide personalized content is highly related to the user's search for personal information and the motive for using entertainment contents. However, the consumer's self-expressive needs and wish to develop good relationships with others are significant for forming interactions between users. Therefore, it is considered that companies can gain the effect of online word of mouth only by inducing prosocial participation in consideration of the social tendencies inherent in consumers, rather than simply by providing information about products and brands.

This study has several limitations as well as suggestions for future research. First, this is a cross-sectional study; thus, it is not possible to discuss causal relationships among recognized SNS motivations, two different interactivities, and 
online word of mouth. However, if a longitudinal study were conducted, a more accurate exploration of the relationship between various factors would be possible. Therefore, it is necessary to accurately verify the causal relationship between SNS motivation and interactivities and various result variables through longitudinal study variables in future research. Second, the interactivity in SNSs was limited to user-to-user interaction and user-to-media interaction in this study, according to previous studies using an integrated approach. However, user to information interactivity should also be considered. If a study looks at these three types of interactivity, it may be able to offer more-specific practical implications through a more detailed analysis of interactivity. Third, this study asked consumers about the SNS channel they used, and a number of respondents answered that they were using multiple SNSs, but no analysis was made considering these characteristics. Therefore, in future studies, an interesting research topic would be to explore what the implications of these characteristics are by distinguishing users from non-users.

Despite these limitations, this study has identified the effect of interactivity from an interpersonal and functional point of view and has identified the effect size of the relationship between interactivities and word of mouth. It is hoped that this study will provide the basis for a stream of further research on users' SNS motivations so that SNS marketers can effectively manage consumers' interactivity intentions and increase business outcomes through their services.

\section{References}

Alberti, R. E., \& Emmons, M. L. (1978). Your perfect right: A guide to assertive behavior. Atascadero, CA: Impact Publishers.

Bass, F. M. (1969). A new product growth model for consumer durables. Management Science, 18(1), 215-227.

Brandtzæg, P. B., \& Heim, J. (2009). Why people use social networking sites. In: International conference on online communities and social computing (pp. 143-152). Berlin, Germany: Springer.

Brooks, R. C. (1957). Word-of-Mouth Advertising in Selling New Products. Journal of Marketing, 22(2), 154-161.

Brown, J., Broderick, A. J., \& Lee, N. (2007). Word of mouth communication within online communities: Conceptualizing the online social network. Journal of Interactive Marketing, 21(3), 2-20.

Burgoon, J. K., Bonito, J. A., Bengtsson, B., Ramirez Jr, A., Dunbar, N. E., \& Miczo, N. (1999). Testing the interactivity model: Communication processes, partner assessments, and the quality of collaborative work. Journal of Management Information Systems, 16(3), 33-56.

Cho, H. O. (2018). Investigating the Effect of Value Characteristics of SNS Users on SNS Usage Motivation, Social Capital, and
Usage Behavior. Journal of Digital Contents Society, 19(2), 351-362.

Choi, N. H., Wang, J., \& Chen, C. (2019). Brand public benefits and consumer engagement. Journal of Asian Finance, Economics and Business, 6(2), 147-160. https://doi.org/10.13106/ jafeb.2019.vol6.no2.147

Chu, S. C., \& Kim, Y. (2011). Determinants of consumer engagement in electronic word-of-mouth (eWOM) in social networking sites. International Journal of Advertising, 30(1), 47-75.

Dholakia, R. R., Zhao, M., Dholakia, N., \& Fortin, D. R. (2000). Interactivity and revisits to websites: A theoretical framework. Retrieved August 10, 2020, from http://ritim.cba.uri.edu/wp/

Downes, E. J., \& McMillan, S. J. (2000). Defining interactivity: A qualitative identification of key dimensions. New Media \& Society, 2(2), 157-179.

Eisingerich, A. B., Auh, S., \& Merlo, O. (2014). Action not words? The role of customer participation and word of mouth in the relationship between service firms' customer satisfaction and sales performance. Journal of Service Research, 17(1), 40-53.

Fornell, C., \& Larcker, D. F. (1981). Evaluating structural equation models with unobservable variables and measurement error. Journal of Marketing Research, 18(1), 39-50.

Hair, J. F., Anderson, R. E., Babin, B. J., \& Black, W. C. (2010). Multivariate data analysis: A global perspective (Vol. 7). Upper Saddle River, NJ: Prentice hall.

Hennig-Thurau, T., Gwinner, K. P., Walsh, G., \& Gremler, D. D. (2004). Electronic word-of-mouth via consumer-opinion platforms: What motivates consumers to articulate themselves on the internet?. Journal of Interactive Marketing, 18(1), $38-52$.

Hoffman, D. L., \& Novak, T. P. (1996). Marketing in Hypermedia Computer Mediated Environments: Conceptual Foundation. Journal of Marketing, 60(3), 50-68.

Jensen, J. F. (1998). Interactivity: Tracking a new concept in media and communication studies. Nordicom Review, 19(1), 185-204.

Johnson, G. J., Bruner II, G. C., \& Kumar, A. (2006). Interactivity and its facets revisited: Theory and empirical test. Journal of Advertising, 35(4), 35-52.

Katz, E., Gurevitch, M., \& Hass, H. (1973). On the use of mass media for important things. American Sociological Review, 38, 164-181.

Katz, E., \& Lazarsfeld, P. F. (1966). Personal Influence, The part played by people in the flow of mass communications. Piscataway, NJ: Transaction Publishers.

Kim, D., \& Jang, S. S. (2019). The psychological and motivational aspects of restaurant experience sharing behavior on social networking sites. Service Business, 13(1), 25-49.

Kim, H., Ko, E., \& Kim, J. (2015). SNS users' para-social relationships with celebrities: social media effects on purchase 
intentions. Journal of Global Scholars of Marketing Science, 25(3), 279-294.

Koo, D. M., \& Lee, J. H. (2011). Inter-relationships among dominance, energetic and tense arousal, and pleasure, and differences in their impacts under online vs. offline environment. Computers in Human Behavior, 27(5), 1740-1750.

Lee, E. E., Kang, H., \& Ahn, H. J. (2017). Word-of-mouth of cultural products through institutional social networks. Sustainability, 9(6), 917-931.

Lew, Z., Walther, J. B., Pang, A., \& Shin, W. (2018). Interactivity in online chat: Conversational contingency and response latency in computer-mediated communication. Journal of ComputerMediated Communication, 23(4), 201-221.

Liu, Y., \& Shrum, L. J. (2002). What is interactivity and is it always such a good thing? Implications of definition, person, and situation for the influence of interactivity on advertising effectiveness. Journal of Advertising, 31(4), 53-64.

McLuhan, M., \& McLuhan, M. A. (1994). Understanding media: The extensions of man. Cambridge, MA: MIT Press.

McMillian, S. J. \& Hwang, J. S. (2002). Measures of Perceived Interactivity: An Exploration of the Role of Direction of Communication, User Control and Time in Shaping Perception of Interactivity. Journal of Advertising, 31(3), 29-42.

Mishra, A., Maheswarappa, S. S., Maity, M., \& Samu, S. (2018). Adolescent's eWOM intentions: An investigation into the roles of peers, the Internet and gender. Journal of Business Research, $86,394-405$.

Newhagen, J. E., Cordes, J. W., \& Levy, M. R. (1995). Nightly@, nbc. com: Audience scope and the perception of interactivity in viewer mail on the Internet. Journal of Communication, 45(3), 164-175.

Papacharissi, Z., \& Rubin, A. M. (2000). Predictors of Internet use. Journal of Broadcasting \& Electronic Media, 44(2), 175-196.

Park, S. (2018). What Do Recreational Shoppers Want to Achieve from Shopping? The Importance of Excitement in Leisure Shopping. Global Business and Finance Review, 23(1), $15-23$.

Salehan, M., Kim, D. J., \& Kim, C. (2017). Use of online social networking services from a theoretical perspective of the motivation-participation-performance framework. Journal of the Association for Information Systems, 18(2), 141-172.

Schumann, D. W., Artis, A., \& Rivera, R. (2001). The future of interactive advertising viewed through an IMC lens. Journal of Interactive Advertising, 1(2), 43-55.
Shapiro, A., \& Swensen, C. H. (1977). Self-disclosure as a function of self-concept and sex. Journal of Personality Assessment, 41(2), 144-149.

Straubhaar, J. D., \& LaRose, R. (2001). Media now: Communication media in the information age. Belmont, CA: Wadsworth Publishing Company.

Tajfel, H., \& Turner, J. (2001). An integrative theory of intergroup conflict. In: M. A. Hogg \& D. Abrams (Eds.), Key readings in social psychology. Intergroup relations: Essential readings (p. 94-109). London, UK: Psychology Press.

Tobing, R. P., Suroso, S., Halim, R. E., \& Alif, G. (2020). Relationship Brand Orientation and Internal Brand Equity at Internet Service Providers: An Organization Change Readiness Effect. Journal of Asian Finance, Economics, and Business, 7(2), 181-193. https://doi.org/10.13106/jafeb.2020.vol7.no2.181

Usher, N. (2016). Interactive journalism: Hackers, data, and code. Champaign, IL: University of Illinois Press.

Vendemia, M. A. (2017). When do consumers buy the company? Perceptions of interactivity in company-consumer interactions on social networking sites. Computers in Human Behavior, 71, 99-109.

Venkatesh, B., \& Sharma, A. K. (2015). Interactive motivational concept: A study of motivation among corporate of Bhopal region in India. Journal of Asian Finance, Economics and Business, 2(2), 35-38. https://doi.org/10.13106/jafeb.2015. vol2.no2.35.

Venkatesh, V., Morris, M. G., Davis, G. B., \& Davis, F. D. (2003). User acceptance of information technology: Toward a unified view. MIS Quarterly, 27(3), 425-478. DOI: $10.2307 / 30036540$

Wang, J. L., Jackson, L. A., Wang, H. Z., \& Gaskin, J. (2015). Predicting social networking site (SNS) use: Personality, attitudes, motivation and internet self-efficacy. Personality and Individual Differences, 80, 119-124.

Wang, Y. \& Fesenmaier, D. R. (2004). Towards Understanding Members' General Participation in and Active Contribution to an Online Travel Community. Tourism Management, 25(6), 709-722.

Won, J., \& Kim, B. Y. (2020). The Effect of Consumer Motivations on Purchase Intention of Online Fashion-Sharing Platform. Journal of Asian Finance, Economics, and Business, 7(6), 197-207. https://doi.org/10.13106/jafeb.2020.vol7.no6.197

Xu, C., Ryan, S., Prybutok, V., \& Wen, C. (2012). It is not for fun: An examination of social network site usage. Information \& Management, 49(5), 210-217. 